\title{
Endovascular Management of Hepatic Encephalopathy
}

\author{
Hieu Le ${ }^{1, \odot}$ Siddhant Thukral2,๑ \\ A. Michael Devane ${ }^{3, \odot}$ \\ ${ }^{1}$ University of Alabama at Birmingham School of Medicine, \\ Birmingham, Alabama, United States \\ ${ }^{2}$ Department - School of Medicine, University of Missouri - Kansas \\ City School of Medicine, Kansas City, Missouri, United States \\ ${ }^{3}$ University of South Carolina School of Medicine Greenville, Prisma \\ Health, Greenville, South Carolina, United States \\ ${ }^{4}$ Department of Radiology, Division of Interventional Radiology, \\ University of Alabama at Birmingham School of Medicine, \\ Birmingham, Alabama, United States
}

\author{
Address for correspondence Rakesh K. Varma, MD, FSIR, \\ Department of Radiology, Division of Interventional Radiology, \\ University of Alabama at Birmingham School of Medicine, 619 19th \\ Street South, NHB H623, Birmingham, AL 35249-6830, \\ United States (e-mail: rvarma@uabmc.edu).
}

\author{
Abstract \\ Keywords \\ - TIPS Reduction \\ - hepatic \\ encephalopathy \\ - TIPS Occlusion \\ - spontaneous porto- \\ systemic shunt
}

Transjugular intrahepatic portosystemic shunt (TIPS) and spontaneous portosystemic shunts (SPSS) may lead to new or worsening hepatic encephalopathy (HE), especially in patients with chronic liver disease. Patients with medically refractory HE (rHE) may benefit from endovascular interventions. In this review, we briefly describe the post-TIPS and SPSS vascular anatomy, pathophysiology, classification, factors associated with $\mathrm{HE}$, and the medical management of HE. In addition, we will discuss current endovascular techniques for $\mathrm{HE}$ management, their advantages, disadvantages, and review of the current literature.

\section{Introduction}

Hepatic encephalopathy (HE) is a neuropsychiatric syndrome typically seen in patients with liver disease with or without portosystemic shunting. ${ }^{1}$ Presentation of HE is comprised of symptoms including confusion, disorientation, abnormal sleep pattern, obtundation, and alterations to the quality of life. ${ }^{2}$ While HE is seen in up to two-thirds of cirrhotic patients, the exact pathophysiology of $\mathrm{HE}$ is complex and yet to be fully understood..$^{1-3}$ Frequently reported factors in the development of HE include elevated serum ammonia, false neurotransmitters, astrocyte swelling, and oxidative stress. ${ }^{1}$ Serum ammonia level is not predictive of HE in chronic liver disease and, therefore, is largely a clinical diagnosis. Ammonia level is an important marker in acute liver failure. ${ }^{4}$ Medical and endovascular management of HE typically focuses on the reduction of plasma ammonia levels; nevertheless, other factors may be deemed more important depending on the patient's clinical condition. ${ }^{5}$

The creation of a transjugular intrahepatic portosystemic shunt (TIPS) is a common inciting factor for developing HE. In a group of cirrhotic patients who primarily receive TIPS for management of decompensated portal hypertension, it is estimated that 5 to $35 \%$ will develop new or worsened HE following TIPS placement. ${ }^{2}$ Although less common, HE can also be a complication of congenital or acquired SPSS. ${ }^{6}$

This review article describes the endovascular techniques for the management of treatment resistant HE secondary to post-TIPS creation and from SPSS. The advantages, disadvantages, and potential consequences of these techniques are reviewed, and we proposed an algorithm for optimal endovascular management. This study is approved by the institutional review board at our institution.
DOI https://doi.org/ $10.1055 / \mathrm{s}-0041-1730869$ ISSN 2457-0214
(C) 2021. Indian Society of Vascular and Interventional Radiology. This is an open access article published by Thieme under the terms of the Creative Commons Attribution-NonDerivative-NonCommercial-License, permitting copying and reproduction so long as the original work is given appropriate credit. Contents may not be used for commercial purposes, or adapted, remixed, transformed or built upon. (https://creativecommons.org/licenses/by-nc-nd/4.0/).

Thieme Medical and Scientific Publishers Pvt. Ltd. A-12, 2nd Floor, Sector 2, Noida-201301 UP, India 


\section{Clinical Presentation}

Symptoms of HE vary between patients ${ }^{2,3}$ ranging from those who experience an abrupt onset of HE symptoms (episodic HE) due to a precipitating event such as infection or gastrointestinal bleed to others who experience a gradual yet persistent onset of HE marked by chronic elevations in serum ammonia, unremitting electrophysiological abnormalities, and recurrent episodes of mental status dysfunction..$^{7-10}$ - Table 1 exhibits the West-Haven criterion, which is used to standardize HE severity objectively. ${ }^{10,11}$ Other helpful psychometric tests for HE include the Reitan number connection test $^{12}$ and the psychometric encephalopathy score. ${ }^{13}$

Ammonia has been implicated ${ }^{2,14}$ as the key molecule in the development of HE due to known toxic cellular effects and its well-documented association in cirrhotic patients. ${ }^{3}$ Additional important factors that are also implicated include hyponatremia, inflammatory cytokines, manganese, reactive oxygen species, and benzodiazepines. ${ }^{3}$ These compounds work to cause astrocyte swelling and dysfunction, which alters the blood-brain barrier and subsequently degrades neuronal function as defined as decreased acetylcholine activity, N-methyl-D-aspartate-glutamate hyperexcitability, and increased use of false neurotransmitters ultimately result in the classic symptoms of HE.

The healthy liver is effective in clearing intestinal compounds implicated in provoking HE. However, decreased hepatic function, as well as shunting (both iatrogenic and congenital/physiological), will negate the liver's ability to remove these substances, thereby causing harmful elevations in serum level. ${ }^{2}$ The conversion rate from compensated to decompensated liver cirrhosis is between 5 and $7 \% .{ }^{11,15}$ Studies estimate that between 10 and $20 \%$ of patients with liver cirrhosis will develop SPSS due to portal hypertension. ${ }^{16}$ The biological advantage conferred by the generation of SPSS is to help the body negate the effects of portal hypertension via shunts allowing blood to bypass the liver. ${ }^{16}$ However, as portal pressures rise, the increasing amount of shunted blood will further contribute to liver disease and subsequent portal hypertension resulting in an enclosed cycle worsening complications. ${ }^{16}$ Recent studies ${ }^{7,17}$ reported that between 46 and $70 \%$ of patients with medically refractory hepatic encephalopathy (rHE) also have radiological evidence of large (diameter $>8 \mathrm{~mm}$ ) SPSS.

Table 1 West-Haven classification of hepatic encephalopathy

\begin{tabular}{|l|l|}
\hline Grade & Criteria \\
\hline 1 & $\begin{array}{l}\text { Trivial lack of awareness, euphoria, shortened attention } \\
\text { span, impaired performance of addition }\end{array}$ \\
\hline 2 & $\begin{array}{l}\text { Lethargy or apathy, minimal disorientation of time } \\
\text { or place, subtle personality changes, inappropriate } \\
\text { behavior }\end{array}$ \\
\hline 3 & $\begin{array}{l}\text { Somnolence to semi-stupor but responsive to verbal } \\
\text { stimuli, confusion, gross disorientation }\end{array}$ \\
\hline 4 & Coma (unresponsive to verbal or noxious stimuli) \\
\hline
\end{tabular}

\section{Medical Management of HE}

Most patients with HE (98\%) will be successfully managed medically without the need for invasive intervention. ${ }^{2.518}$ Treatment typically has two components: the induction phase and the maintenance of remission phase. Most cases of significant HE are precipitated by infection, gastrointestinal bleeding, or medications. The key to treat $\mathrm{HE}$ is to eliminate the precipitating factors. A diet low in animal protein and high in plant protein is recommended to prevent HE. ${ }^{19}$ Additionally, first-line treatment for the management of HE includes the use of nonabsorbable disaccharides such as lactulose. ${ }^{20}$ Lactulose is metabolized to lactic acid and acetic acid by gut bacteria, which effectively lowers intestinal $\mathrm{pH}$, thereby reducing the survival of urease producing organisms and subsequently promoting the conversion of ammonia to the less systemically absorbed ammonium. ${ }^{20}$ Additionally, lactulose acts as an osmotic agent that further promotes the fecal excretion of nitrogen. ${ }^{20-22}$ The usual initial dose of lactulose is $25 \mathrm{~mL}$ ( $16.7 \mathrm{~g}$ ) oral syrup every 1 to 2 hours until the patient has two soft bowel movements with subsequent dose adjusted to 15 to $45 \mathrm{~mL}(10-30 \mathrm{~g})$ two to four times daily to have two to three soft bowel movements per day. ${ }^{20-22}$

Antimicrobial therapy, comprised of drugs such as rifaximin, neomycin, and metronidazole, is also commonly used to promote a favorable gut microbiome that reduces the endogenous production of nitrogenous compounds. ${ }^{20}$ Among antibiotics used, rifaximin (550 mg twice daily) is often preferred due to its low systemic absorption, broad-spectrum coverage, and proven clinical efficacy from large multicentered studies. ${ }^{20,23}$ However, rifaximin should be used as an adjunct therapy to lactulose..$^{20}$ Oral neomycin and metronidazole are not routinely used due to major potential adverse effects of ototoxicity or nephrotoxicity and neurotoxicity, respectively. ${ }^{20}$

\section{Post-TIPS and SPSS Vascular Anatomy}

During TIPS procedure, a communication is created between the portal vein and the hepatic vein. The result is shunting the portal circulation directly into the systemic circulation bypassing the liver, which will reduce the portosystemic gradient (PSG). However, this shunt can exacerbate HE.

SPSS can range from asymptomatic presentation to recurrent and rHE, ultimately culminating in progressive hepatic failure in cirrhotics. Commonly seen shunts in cirrhotics include splenorenal, gastrorenal, and dilated paraumbilical veins. Broadly these can be divided into the ones draining into the superior vena cava (i.e., splenocoronary/pulmonary, splenoazygos, and pancreaticoduodenal/hemiazygos) and the one's draining into the inferior vena cava (i.e., gastrorenal, gastrocaval, gastro/splenogonadal, splenorenal, splenoadrenorenal, splenocaval, transsplenic and mesentericogonadal/renal/caval) ( - Fig. 1). 


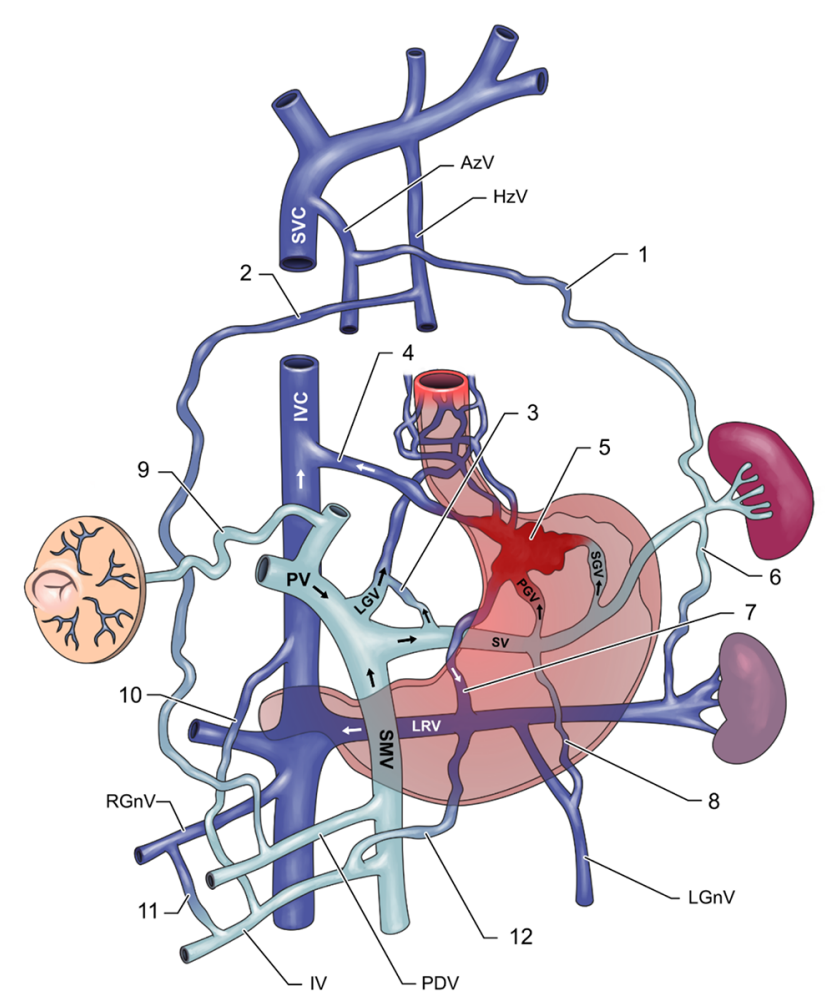

Fig. 1 (1) Splenoazygos shunt, (2) pancreaticoduodenal/hemiazygos shunt, (3) splenocoronary shunt, (4) gastrocaval shunt, (5) gastric varices, (6) splenorenal shunt, (7) gastrorenal shunt, (8) splenogonadal shunt, (9) dilated paraumbilical vein (caput medusae), (10) mesenteric-caval shunt, (11) mesenteric-gonadal shunt, and (12) mesenteric-renal shunt. AzV, azygos vein; $\mathrm{HzV}$, hemiazygos vein; LGV, left gastric (or coronary) vein; LGnV, left gonadal vein; LRV, left renal vein; IVC, inferior vena cava; IV, ileocolic vein; PDV, pancreaticoduodenal vein; PGV, posterior gastric vein; $\mathrm{PV}$, portal vein; RGnV, right gonadal vein; SCV, superior vena cava; SGV, short gastric veins; SMV, superior mesenteric vein; SV, splenic vein.

\section{HE Management with Endovascular Techniques}

Management for patients with rHE is complex with liver transplantation serving to be the ultimate therapy. ${ }^{22}$ Patient selection for TIPS, therefore, is the most critical method for the prevention of rHE with the following being the most suggestive predictors for its development: age over 65 , diabetes mellitus, previous HE (West-Haven Grade $\geq 2$ ), Child-Turcotte-Pugh $(\mathrm{CTP})>10$, and higher Model for End-Stage Liver Disease (MELD) score. ${ }^{24-27}$ Patients who do not respond to medical management will require a more invasive approach. HE management with endovascular techniques can be subdivided based on the presence of TIPS, SPSS, or a combination of both (-Fig. 2). However, endovascular management does not provide clinical improvement in the setting of HE with liver failure, with liver transplantation to be the only option.

\section{TIPS Reduction/Occlusion}

Endovascular therapies for the treatment of post-TIPS rHE focus on decreasing the shunting of intestinally derived toxins while increasing perfusion to hepatocytes ${ }^{2,22}$ by reducing or occluding the lumen of the shunt. TIPS occlusion ( - Fig. 3), while effective at reducing rHE, is associated with a high risk of variceal bleeding, ascites, pleural effusions, and hemodynamic changes with increased portal pressure and cardiac load secondary to increased pulmonary and systemic resistances due to acute splanchnic venous engorgement. ${ }^{7,28-30}$ TIPS occlusion cannot be postoperatively titrated as compared with certain shunt reduction techniques; ${ }^{31}$ hence, TIPS reduction is favored compared with occlusion. ${ }^{22}$ Furthermore, the outcome of these treatments

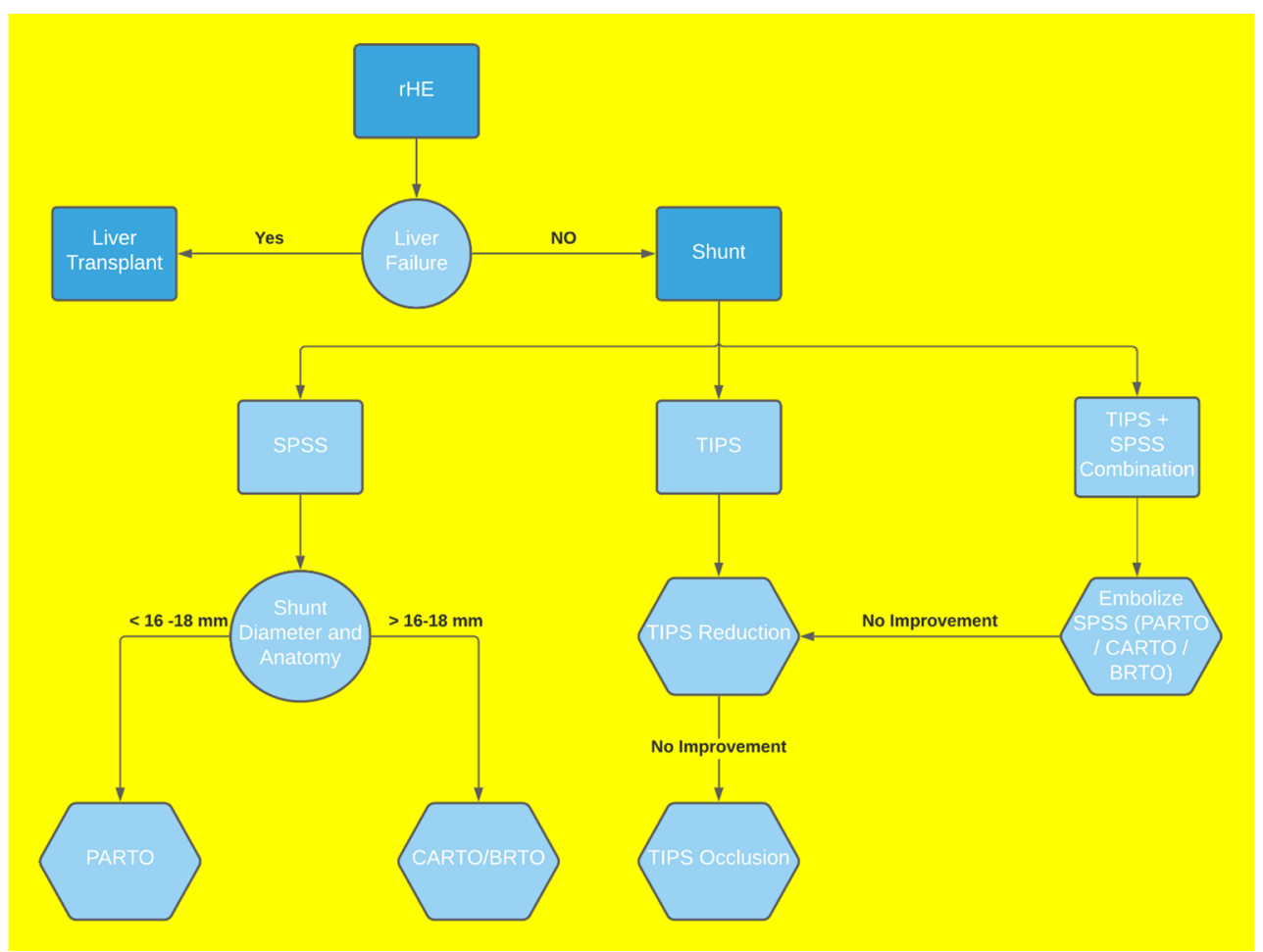

Fig. 2 Algorithm for endovascular management for treatment resistant hepatic encephalopathy. 


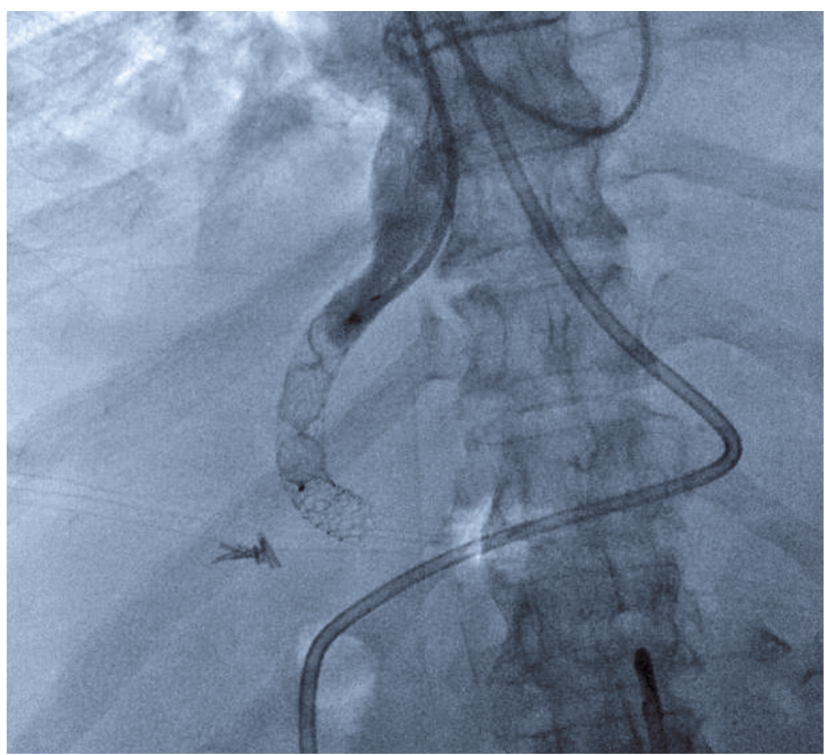

Fig. 3 Transjugular intrahepatic portosystemic shunt occlusion using an Amplatzer II plug in a case of refractory hepatic encephalopathy.

is difficult to predict, given the overall sicker population of patients that require them. ${ }^{7,22,28,29,31,32}$ Thus, TIPS occlusion is reserved for patient with no improvement in HE after a TIPS reduction had been attempted. TIPS reduction preserves TIPS function, reducing exacerbation of portal hypertension while maintaining portal perfusion and hepatic detoxification from gut-derived nitrogenous compounds. ${ }^{33}$ For these reasons, endovascular techniques have refined toward stent utilization for graded shunt reduction..$^{22}$ There is sparse data on the target PSG post-TIPS reduction. Sze et al published in their series of six patients who underwent TIPS reduction for medically refractory HE with the mean and median PSG increase by $8 \mathrm{~mm} \mathrm{Hg}$ for a final gradient of $17 \mathrm{~mm} \mathrm{Hg}$ (range: $10-20 \mathrm{~mm} \mathrm{Hg})^{34}$

Shunt reduction is typically successful in patients with HE with a published clinical success rate of up to $71 \% .{ }^{22}$ However, the results of Hauenstein et al concluded that TIPS reduction to treat HE demonstrated clinical success only in patients with preserved underlying liver functions as opposed to patients with acute liver failure. ${ }^{35}$ Similarly, Schultheiss et al, in their series of 17 patients with median bilirubin at TIPS reduction of $2.6 \mathrm{mg} / \mathrm{dL}$, demonstrated improvement of $\mathrm{HE}$ in 11 patients with no benefit of shunt reduction or occlusion in patients with acute liver failure. ${ }^{36}$ Hence, TIPS reduction or occlusion for treating acute liver failure should be carefully evaluated as there may be no clinical improvement.

\section{Controlled Expansion Endoprosthesis}

Due to the high incidence of HE post-TIPS creation, many centers adopted under dilation of the stent graft to reduce the blood shunted through the liver and reduce the incidence of HE. ${ }^{37}$ However, studies have shown that these stents grafts undergo passive dilation to their actual size, thus limiting the potential benefit of under dilation. ${ }^{37}$ The Viatorr Controlled Expansion stents (VCX) (GORE and Associates, Flagstaff,
Arizona, United States) are newer generation stents with controlled expansion sleeve designed to optimize the diameter and prevent spontaneous expansion in under dilated Viatorr stents (-Fig. 4). Miraglia et al deployed TIPS VCX stents in 75 patients with 69 patients having their TIPS VCX stent dilated to $8 \mathrm{~mm}$ with a mean follow-up of 5.8 months. Their study concluded no passive dilation beyond the titrated diameter with clinical success of $88 \%$ and low HE rate of $6 \% .^{38}$ Thus, patient needing TIPS with anticipated higher risk of developing HE might benefit from this technique for the initial stent placement. However, since the diameter cannot be reduced to less than $8 \mathrm{~mm}$, this technique would be ineffective if the patient develops post-TIPS HE.

\section{Parallel Stent Graft Technique}

TIPS reduction by the parallel placement of a self-expanding stent graft and balloon-expandable stent is frequently used to manage HE ( - Fig. 5). ${ }^{33}$ Parallel stent grafts allow for biluminal adjustment of shunt diameter to manage the portosystemic pressure gradient to optimize TIPS configuration and flow. ${ }^{33}$ Previous trials ${ }^{33}$ have demonstrated clinical improvement in $62.5 \%$ of their patients and complete resolution of $\mathrm{HE}$ in $50 \%$ of their patients with the parallel stent graft technique.

\section{Sheath-Controlled Technique}

While shunt reduction is effective, a common concern among interventionalists is stent migration during deployment. ${ }^{31,39-41}$ The use of the sheath-controlled technique in which a constraining sheath is utilized during the deployment

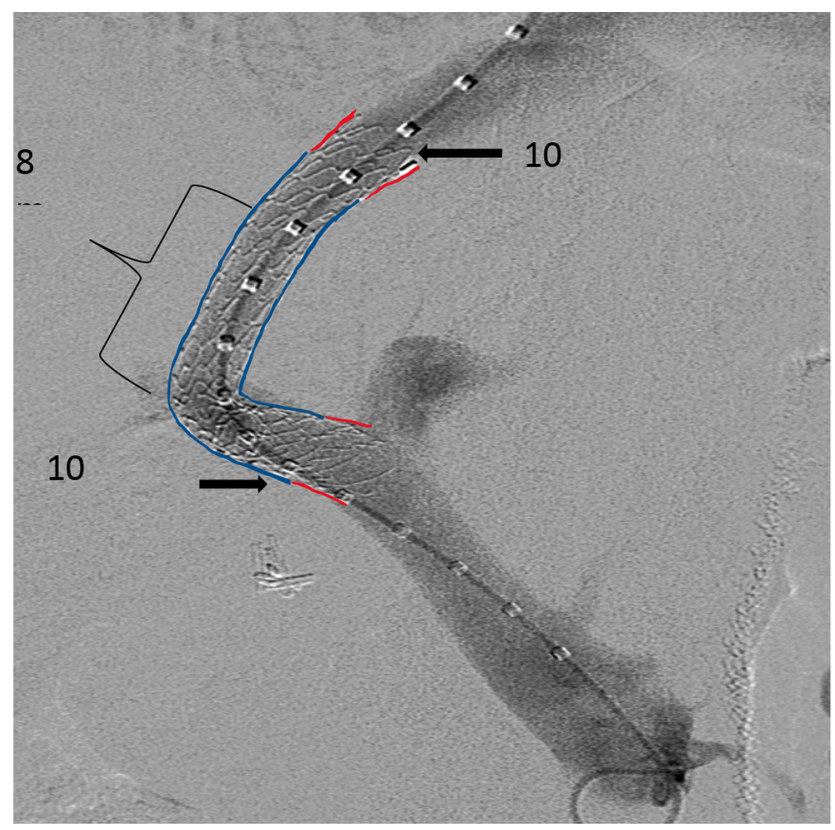

Fig. 4 Transjugular intrahepatic portosystemic shunt (TIPS) with Viatorr Controlled Expansion stents (VCX) in a 62-year-old woman with nonalcoholic steatohepatitis cirrhosis, refractory ascites, and grade I hepatic encephalopathy. $8-10 \mathrm{~mm} \times 6 \mathrm{~cm} / 2 \mathrm{~cm}$ VCX stent was expanded to $8 \mathrm{~mm}$ with portosystemic gradient reduction pre-TIPS-14 $\mathrm{mm} \mathrm{Hg}$ to post-TIPS-6mm Hg. 
of polytetrafluoroethylene-covered balloon deployable stent allows for additional control during the procedure, minimized stent migration, and creation of an hourglass-shaped stent contour ( - Fig. 6). ${ }^{39}$ A study by Blue et al found a $100 \%$ technical success rate of shunt reduction, no stent migration during deployment, and all patients experienced improvement of HE utilizing the sheath-controlled technique. ${ }^{39}$ The study concluded that the sheath-controlled technique is safe and effective and minimizes stent migration.

\section{Hourglass-Shaped Technique}

A balloon-expandable polytetrafluoroethylene stent-graft is also utilized to achieve shunt reduction for rHE by tying the midportion with an absorbable polyglactin suture and inflated within the TIPS stent graft to create an hourglass shape. By dilating both ends or middle portion of the shunt, the PSG can be increase or decrease, respectively, according to the patient's clinical condition..$^{42}$ In a series with 12 patients by Fanelli et al, there was a 100\% technical success rate and $50 \%$ clinical success with a mean follow-up period of 73.9 weeks. ${ }^{42}$ This technique has the advantage to further dilate the stent should the sequalae of portal hypertension reoccur and less expensive than other procedures as it only utilizes one stent. ${ }^{42}$ The main disadvantage to this technique is higher incidence of hepatic or portal vein stenosis ${ }^{43}$ and lack of data on long-term patency.

\section{Self-Expanding Stents Technique}

The use of self-expanding stents has been documented for the achievement of SPSS reduction. Haskal and Middlebrook ${ }^{44}$ reported on a wall stent that was constrained with a 3-0 silk suture to create an hourglass shape. This led to a reduction in portosystemic shunting similar to that utilized by a balloon-expandable stent. ${ }^{39,44}$ Madoff et al
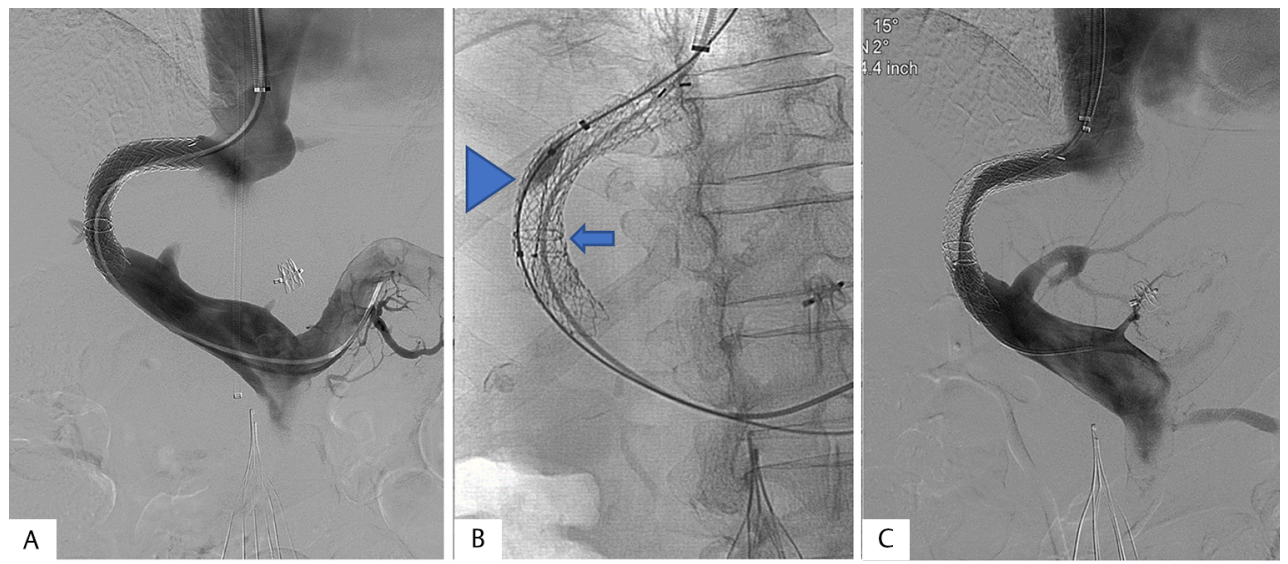

Fig. 5 A 67-year-old woman with alcoholic cirrhosis and refractory hepatic encephalopathy. (A) S/P transjugular intrahepatic portosystemic shunt (TIPS) placement for variceal bleeding from alcoholic cirrhosis. (B) A self-expandable stent graft and a balloon-expandable stent in a parallel configuration, giving an hourglass-shape to the TIPS shunt, thereby reducing the diameter. (C) Digital subtraction angiography portogram S/P TIPS shunt reduction with portosystemic gradient increase from 2 to $5 \mathrm{~mm} \mathrm{Hg}$.
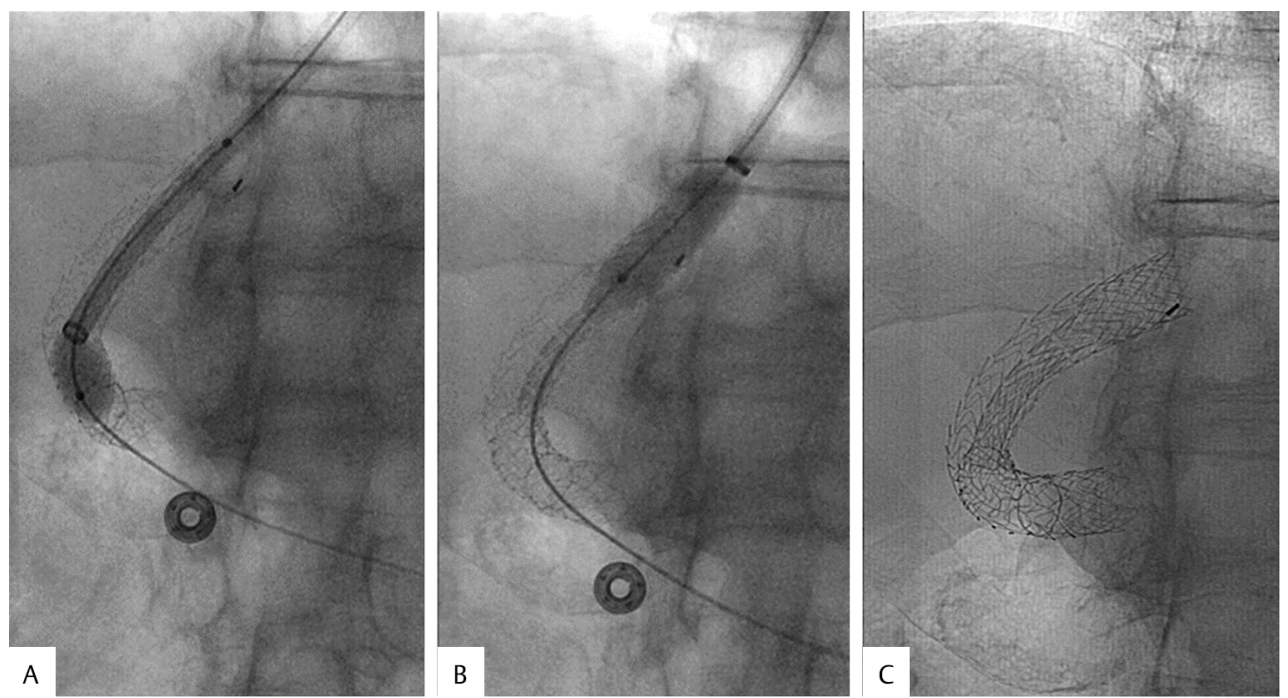

Fig. 6 A 53-year-old woman with alcoholic cirrhosis with refractory hepatic encephalopathy. (A) The stent is buttressed by the sheath during balloon retraction followed by the (B) proximal portion of the stent being angioplastied to complete the hourglass shape and the (C) central portion to the stent dilated up to $5 \mathrm{~mm}$. 
evaluated the feasibility of suture constrained endograft for the management of TIPS-related HE. ${ }^{45}$ Their study reported a $100 \%$ technical success rate with a mean increase of PSG of $196 \%$ or 8.3 to $17.6 \mathrm{~mm} \mathrm{Hg}$ following reduction. However, the diameter of suture contained stents cannot be titrated once deployed as compared with the sheath-assisted controlled stent graft technique.

\section{Spontaneous Portosystemic Shunt Occlusion}

Endovascular therapies for the treatment of HE due to SPSS focus on occluding the lumen of the shunt. A systematic review and meta-analysis of studies by Patil et al concluded that SPSS occlusion or embolization was safe, with minimal complications in patients with good liver function. Patients with a CTP score $>11,{ }^{18} \mathrm{MELD} \geq 15$, and/or baseline presence of hepatocellular carcinoma ${ }^{46}$ were unlikely to benefit from shunt occlusion due to very high mortality and recurrent or persistent HE. These patients would need evaluation and enlist for liver transplantation.
Balloon-occluded retrograde transvenous obliteration (BRTO) was one of the initially practiced minimally invasive endovascular methods for the occlusion of gastric vein $(\mathrm{GV})$ and shunts that contribute to rHE ( - Fig. 7$){ }^{47}$ Studies by Bessari and Lightfoot as well as Koito et al ${ }^{30,48}$ have shown a 79 to $100 \%$ technical success rate of BRTO. However, the major drawbacks were balloon rupture ( $8.7 \%$ of cases), embolization of sclerosant to the systemic circulation, ${ }^{49}$ and prolonged catheter indwelling times ranging from 4 to 20 hours. ${ }^{50,51}$

Several modifications to BRTO have been performed to improve patient safety and technical concerns. In contrast to BRTO, plug-assisted retrograde transvenous obliteration (PARTO) utilizes a permanent occlusive device such as Amplatzer vascular plug to occlude varices, thereby reducing procedure time and risk of sclerosant embolization ${ }^{50}$ (-Fig. 8). In addition, there is no balloon catheter indwelling times and no added risk of balloon rupture. Previous studies ${ }^{49,50}$ have demonstrated equivalent, if not greater treatment efficacy, in treatment of GV with PARTO as compared with BRTO. However, the plugs are currently only available
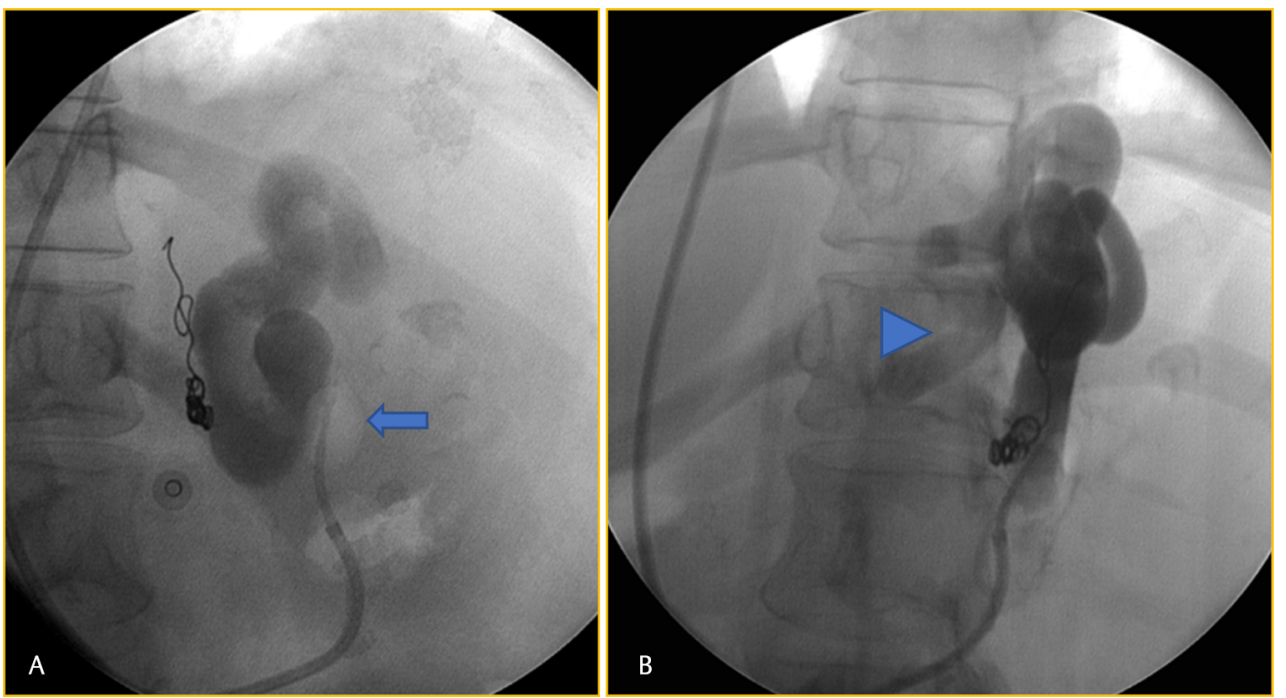

Fig. 7 Balloon-occluded retrograde transvenous obliteration: A 47-year-old woman with nonalcoholic steatohepatitis and Grade II hepatic encephalopathy. (A) Sclerosant mixture (1cc Lipiodol: 2cc STS: 3cc air) injected into the varices after coil embolization of the collateral vein, balloon (air filled, arrow). (B) Oblique view with opacification of the afferent vein (arrowhead), the end point to injection.
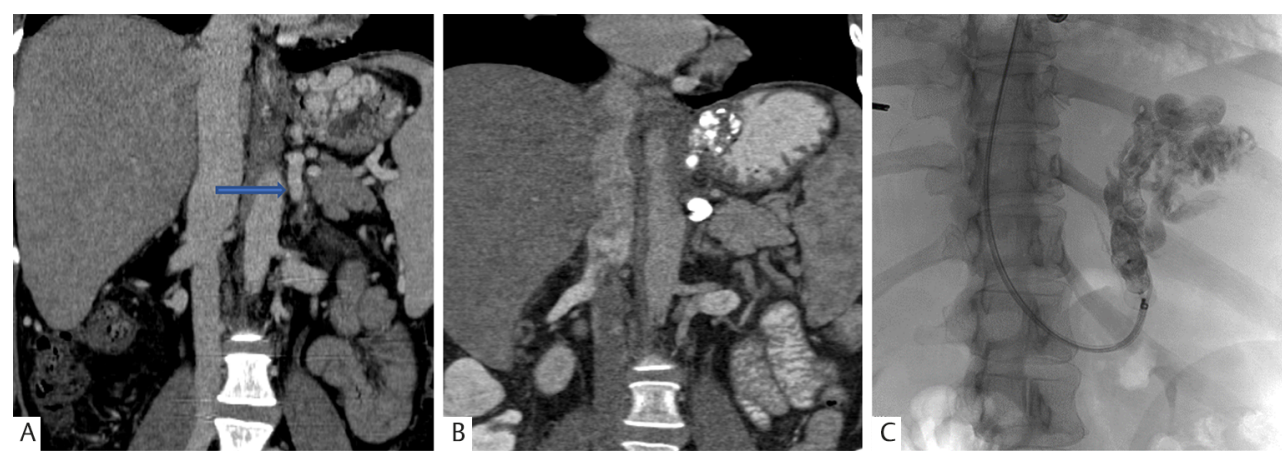

Fig. 8 Plug-assisted retrograde transvenous obliteration (PARTO): A 68-year-old male with hepatic encephalopathy. (A) Pre-PARTO coronal computed tomography (CT) demonstrating a contrast enhanced gastrorenal shunt (arrow), (B) post-PARTO coronal CT and (C) fluoroscopic image showing lipiodol retention into the shunt and the Amplatzer vascular plug at the outflow. The typical ratio of the emulsion is 1:2:2 of lipiodol: sodium tetradecyl sulfate: air. 
up to $22 \mathrm{~mm}$ diameter, restricting treatable shunt size to 16 to $18 \mathrm{~mm}$. Technical limitations of PARTO include tortuous and angulated shunts limiting sheath advancement for plug deployment. In such scenarios, coil-assisted retrograde transvenous obliteration (CARTO) serves as an alternative method for shunt occlusion. CARTO is a modified technique that uses coils and Gelfoam slurry to achieve shunt occlusion in situations where shunt size, shunt angle, or vessel tortuosity is not conducive for vascular plug or balloon occlusion..$^{51-53}$ CARTO may either be performed by deploying coils and Gelfoam slurry through a microcatheter (CARTO 1 Procedure) ( - Fig. 9) or by deploying coils following successful shunt stasis from occlusion balloon (CARTO 2 Procedure) ( - Fig. 10). ${ }^{51}$ As compared with BRTO and PARTO, clinical data ${ }^{49,51-53}$ has suggested CARTO as a safer alternative for shunt occlusion with comparable treatment efficacy. Limitations of CARTO include high procedure costs for cases that require multiple detachable coils. ${ }^{51}$ The approximate average time to procedure completion in BRTO, PARTO, and CARTO ranges from 8 to 10 hours, 2 to 3 hours, and 30 minutes to 1 hour, respectively, as per multiple studies. ${ }^{54}$ The overall reported technical success rates for CARTO and PARTO from three recent large studies were $100 \%$ with 49 to $92 \%$ of patients having clinically significant improvement from HE during the follow-up period at 6 to 27 months. ${ }^{7,46,55}$
Similar to BRTO, when the varix or shunt is embolized in an antegrade fashion, that is, in the direction of the inflow veins, the technique is termed as balloon antegrade transvenous obliteration (BATO). These can be either performed via a preexisting TIPS called as trans-TIPS BATO (-Fig. 11) or transhepatic. ${ }^{51}$ In general, BATO (specifically percutaneous transhepatic obliteration) is considered as an adjunct or alternative to BRTO when BRTO fails completely or partially in obliterating the gastric variceal system. As an adjunct to BRTO, BATO increases the technical success rates and decreases the overall risk of sclerosant leak. ${ }^{51} \mathrm{~A}$ combined technique with BATO and CARTO/PARTO termed retrograde-antegrade accelerated trap obliteration where both the inflow and outflow veins are embolized simultaneously with coils or plugs has been described for obliteration of bleeding gastric varices with promising results. ${ }^{56}$ However, there is currently no study comparing the clinical efficacy of antegrade versus retrograde embolization techniques in the management of rHE.

Overall, studies have reported very few major adverse effects related to shunt embolization. The recurrence of symptomatic portal hypertension (varices and ascites) was seen in all series ( - Table 2) ${ }^{7,18,46,55,57}$ The most reported adverse event was worsening esophageal varices (19-46\%) with rebleeding complications around $10 \%{ }^{51}$ Newly developed or increased amount of ascites was noted in 9.5 to $33 \%$ of studies with a
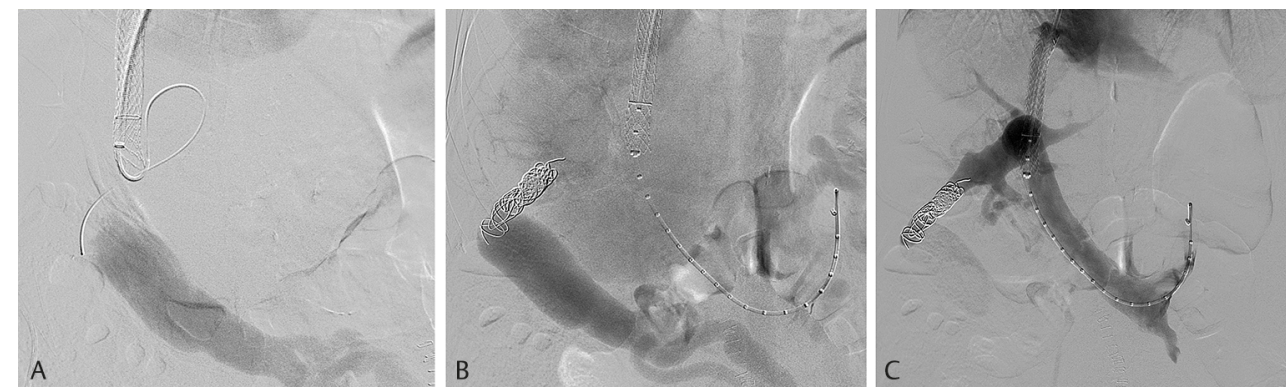

Fig. 9 Coil-assisted transvenous obliteration: A 68-year-old woman S/P transjugular intrahepatic portosystemic shunt (TIPS) for refractory ascites complicated by intermittent hepatic encephalopathy. (A) Trans-TIPS venogram showing filling of the large paraumbilical varix, (B) coils deployed into the varix, and $(\mathbf{C})$ postembolization portal venogram demonstrating patent TIPS with central portal vein perfusion and thrombosed paraumbilical varix.
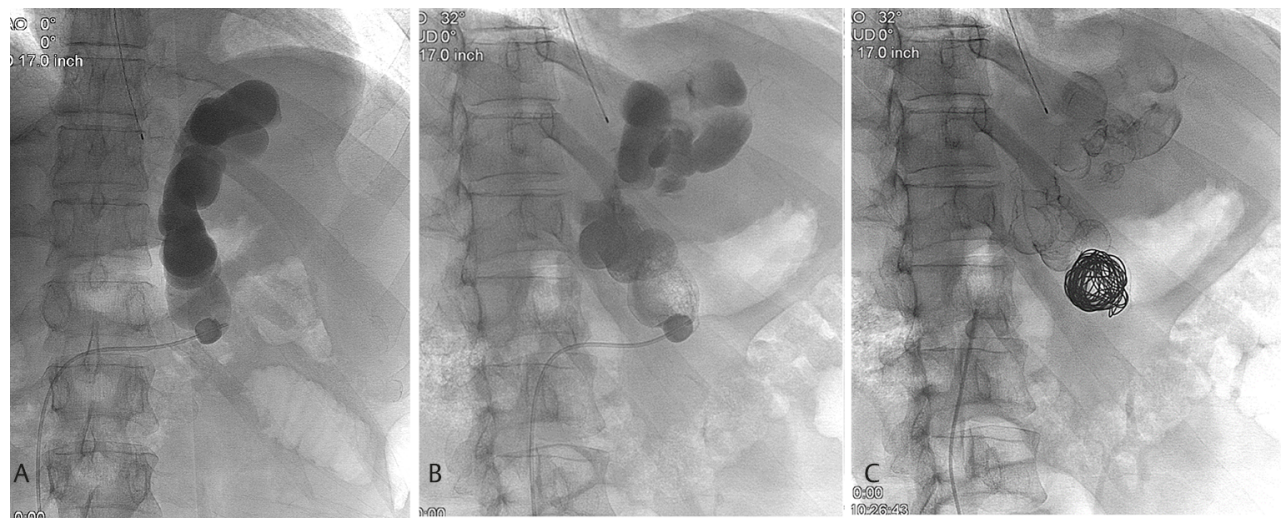

Fig. 10 Coil-assisted retrograde transvenous obliteration: A 40-year-old male with alcoholic cirrhosis and intermittent hepatic encephalopathy. (A) Balloon-occluded venogram showing filling of the gastric varix, (B) sclerosant being injected into the varix, and (C) after coil embolization through the balloon catheter. 
pooled percentage of $18.3 \%$. Rare complication may include hemoperitoneum, hemobilia, bacterial cholangitis, spontaneous bacterial peritonitis, capsular bleeding, and portal vein thrombosis. Balloon rupture in BRTO procedures may expose patients to sclerosing agents that have been associated with hemolysis, renal failure, cardiogenic shock, and disseminated intravascular coagulation. ${ }^{31,50,51}$

Combination of TIPS and retrograde transvenous obliteration in the management of gastric variceal bleeding has been shown to have higher clinical efficacy ${ }^{58}$ however, there is lack of data regarding combination therapy for the management of rHE. As the diameter of a TIPS shunt can be calibrated to meet the goal, we propose embolizing a significant diameter spontaneous shunt prior to TIPS reduction for the management of rHE.

\section{Conclusion}

Treatment refractory HE, though uncommon, often requires invasive endovascular therapy. Careful patient selection for elective creation of portosystemic shunt still remains the key

Table 2 Major studies on shunt embolization for recurrent or rHE

\begin{tabular}{|c|c|c|c|c|c|c|}
\hline Author/country/year & $\begin{array}{l}\begin{array}{l}\text { Patients } \\
(n / n)^{\mathrm{a}}\end{array} \\
\text { Study type }\end{array}$ & $\begin{array}{l}\text { Techniques } \\
\text { utilized }\end{array}$ & $\begin{array}{l}\text { Technical } \\
\text { success } \\
\text { rate (\%) } \\
\text { Follow-up } \\
\text { period }\end{array}$ & $\begin{array}{l}\text { Long-term } \\
\text { outcomes }\end{array}$ & $\begin{array}{l}\text { Major } \\
\text { complication } \\
\text { PHT clinical events } \\
\text { and complications }\end{array}$ & Unique findings \\
\hline \multirow{3}{*}{$\begin{array}{l}\text { Philips et al/ } \\
\text { India/2017 }\end{array}$} & $21 / 21$ & \multirow{3}{*}{$\begin{array}{l}\text { BRTO, CARTO, } \\
\text { PARTO, } \\
\text { Gelfoam, } \\
\text { surgical shunt } \\
\text { occlusion }\end{array}$} & 95.2 & \multirow{3}{*}{$\begin{array}{l}71 \% \text { showed } \\
\text { no overt HE } \\
\text { at } 9 \text { months }\end{array}$} & One death due to & \multirow{3}{*}{$\begin{array}{l}\text { Largest single-center } \\
\text { series, CTP }>11 \text { as the } \\
\text { cutoff for excluding } \\
\text { patients from shunt } \\
\text { embolization, first } \\
\text { to demonstrate } \\
\text { amelioration of } \\
\text { cirrhosis-associated } \\
\text { Parkinson disease with } \\
\text { shunt embolization }\end{array}$} \\
\hline & \multirow[t]{2}{*}{$\begin{array}{l}\text { Retrospective, } \\
\text { single center }\end{array}$} & & \multirow[t]{2}{*}{$\begin{array}{l}1-9 \\
\text { months }\end{array}$} & & $\begin{array}{l}\text { hemoperitoneum } \\
\text { and multiple organ } \\
\text { failure }\end{array}$ & \\
\hline & & & & & $\begin{array}{l}\text { AVB in one, } \\
\text { new-onset ascites } \\
\text { in two }\end{array}$ & \\
\hline \multirow[t]{3}{*}{ Lynn et al/USA/2016 55} & $18 / 20$ & \multirow{3}{*}{$\begin{array}{l}\text { CARTO, } \\
\text { PARTO }\end{array}$} & 100 & \multirow{3}{*}{$\begin{array}{l}\text { 92\% showed } \\
\text { no overt } \\
\text { HE at 6-12 } \\
\text { months }\end{array}$} & Hemobilia and & \multirow{3}{*}{$\begin{array}{l}\text { Inclusion of patients } \\
\text { with prior liver } \\
\text { transplantation }\end{array}$} \\
\hline & \multirow{2}{*}{$\begin{array}{l}\text { Retrospective, } \\
\text { single center }\end{array}$} & & \multirow[t]{2}{*}{$\begin{array}{l}\text { Median } 12 \\
\text { months }\end{array}$} & & $\begin{array}{l}\text { bacterial cholangitis } \\
\text { in one }\end{array}$ & \\
\hline & & & & & $\begin{array}{l}\text { Ascites in six } \\
\text { patients }\end{array}$ & \\
\hline \multirow[t]{2}{*}{ An et al/Korea/2014 } & $17 / 17$ & \multirow{2}{*}{$\begin{array}{l}\text { CARTO, } \\
\text { PARTO, } \\
\text { Gelfoam }\end{array}$} & 100 & \multirow{2}{*}{$\begin{array}{l}60 \% \text { showed } \\
\text { no overt HE } \\
\text { at } 24 \text { months }\end{array}$} & None & \multirow[b]{2}{*}{$\begin{array}{l}\text { Presence of a matched } \\
\text { control group, increase } \\
\text { in liver volume post- } \\
\text { shunt embolization, } \\
\text { MELD } \geq 15 \text {, and base- } \\
\text { line presence of hepa- } \\
\text { tocellular carcinoma } \\
\text { predicted mortality at } \\
\text { the end of } 1 \text { year }\end{array}$} \\
\hline & $\begin{array}{l}\text { Retrospective, } \\
\text { single center }\end{array}$ & & $\begin{array}{l}\text { Median } 19 \\
\text { months }\end{array}$ & & $\begin{array}{l}\text { Ascites in three } \\
\text { patients }\end{array}$ & \\
\hline \multirow{2}{*}{$\begin{array}{l}\text { Naeshiro et al/ } \\
\text { Japan/2014 }\end{array}$} & $14 / 14$ & \multirow[t]{2}{*}{ BRTO, CARTO } & 92.9 & \multirow{2}{*}{$\begin{array}{l}93 \% \text { showed } \\
\text { no overt HE } \\
\text { at } 27 \text { months }\end{array}$} & None & \multirow[b]{2}{*}{$\begin{array}{l}\text { Suggested CTP } \leq 10 \text { as } \\
\text { the cut-off for selection } \\
\text { for shunt embolization } \\
\text { to prevent postproce- } \\
\text { dural complications, } \\
\text { suggested splenec- } \\
\text { tomy or splenic artery } \\
\text { embolization postshunt } \\
\text { embolization to prevent } \\
\text { worsening of PHT } \\
\text { complications }\end{array}$} \\
\hline & $\begin{array}{l}\text { Retrospective, } \\
\text { single center }\end{array}$ & & $\begin{array}{l}\text { Median } 27 \\
\text { months }\end{array}$ & & None & \\
\hline \multirow{2}{*}{$\begin{array}{l}\text { Laleman et al/ } \\
\text { Europe } / 2013^{7}\end{array}$} & $37 / 37$ & \multirow{2}{*}{$\begin{array}{l}\text { CARTO, } \\
\text { PARTO }\end{array}$} & 100 & \multirow{2}{*}{$\begin{array}{l}49 \% \text { showed } \\
\text { no overt HE } \\
\text { at } 24 \text { months }\end{array}$} & Capsular bleeding & \multirow{2}{*}{$\begin{array}{l}\text { Multicenter study, } \\
\text { MELD } \geq 11 \text {, higher risk } \\
\text { of recurrence of } \mathrm{HE}\end{array}$} \\
\hline & $\begin{array}{l}\text { Retrospective, } \\
\text { multiple } \\
\text { center }\end{array}$ & & $\begin{array}{l}\text { Mean } 697 \\
\text { days }\end{array}$ & & $\begin{array}{l}\text { Ascites in six } \\
\text { patients, spontane- } \\
\text { ous bacterial perito- } \\
\text { nitis in two, portal } \\
\text { vein thrombosis in } \\
\text { four patients }\end{array}$ & \\
\hline
\end{tabular}

Abbreviations: AvB, acute variceal bleeding; BRTO, balloon-assisted retrograde transvenous occlusion; CARTO, coil-assisted retrograde transvenous occlusion; CTP, Child-Pugh-Turcotte score; MELD, model for end-stage liver disease; PARTO, plug-assisted retrograde transvenous occlusion; PHT, portal hypertension; rHE, refractory hepatic encephalopathy.

Source: Modified from Philips CA, Rajesh S, Augustine P, Padsalgi G, Ahamed R. Portosystemic shunts and refractory hepatic encephalopathy: patient selection and current options. Hepat Med 2019;11:23-34.

aData shown as number of patients who completed a minimum of 1 month follow-up/total number of patients in the study. 


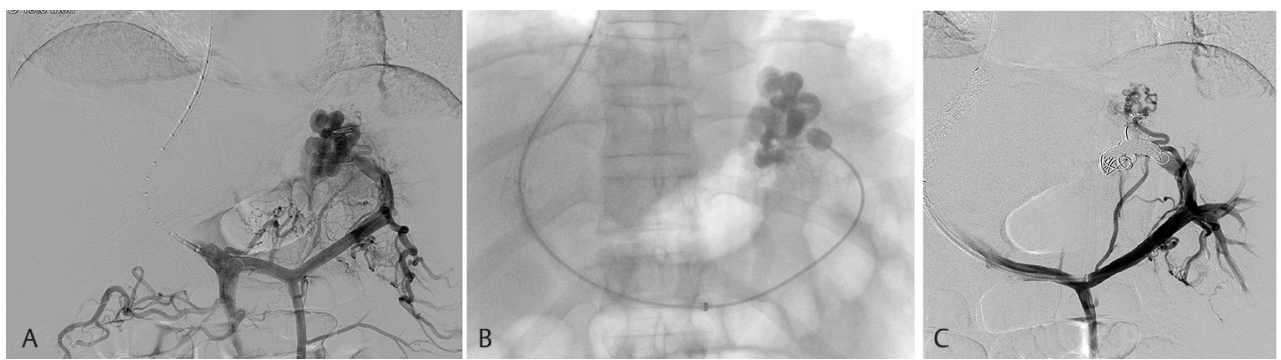

Fig. 11 Trans- TIPS balloon antegrade transvenous obliteration: A 64-year-old gentleman with alcoholic cirrhosis with associated ascites and recurrent variceal bleeding despite banding/clipping and medical therapy. (A) Trans-TIPS venogram showing retrograde flow within an enlarged/dilated splenic vein with filling of multiple splenic and gastric varices, (B) sclerosant being injected into the varix with balloon-occlusion, and (C) multiple coils were then deployed for embolization.

for prevention of post-TIPS HE. Endovascular techniques such as TIPS reduction or occlusion, BRTO, PARTO, and CARTO are safe and efficacious in patients with good liver function. Patients with high MELD score or poor liver function with HE have guarded outcomes from these interventions. TIPS reduction/occlusion and SPSS embolization can exaggerate portal hypertension.

\section{Conflict of Interest}

A.M.D. reports personal fees from Boston Scientific, personal fees from Johnson and Johnson Ethicon, unrelated to the submitted work. S.T. reports grants from National Institutes of Health, during the conduct of the study, unrelated to the submitted work.

\section{Funding}

S.T. received grants from the National Center for Advancing Translational Sciences of the National Institutes of Health under Award Number TL1TR002344.

\section{References}

1 Mina Shaker WDC. Hepatic Encephalopathy. June 2014 August 2017 [cited 2019 09/16/2019]; Available from: http:// www.clevelandclinicmeded.com/medicalpubs/diseasemanagement/hepatology/hepatic-encephalopathy/\#summary. Accessed February 21, 2021

2 Madoff DC, Wallace MJ, Ahrar K, Saxon RR. TIPS-related hepatic encephalopathy: management options with novel endovascular techniques. Radiographics 2004;24(1):21-36

3 Frederick RT. Current concepts in the pathophysiology and management of hepatic encephalopathy. Gastroenterol Hepatol (N Y) 2011;7(4):222-233

4 Ge PS, Runyon BA. Serum ammonia level for the evaluation of hepatic encephalopathy. JAMA 2014;312(6):643-644

5 Wright G, Chattree A, Jalan R. Management of hepatic encephalopathy. Int J Hepatol 2011;2011:841407

6 Qi X, Ye C, Hou Y, Guo X. A large spontaneous intrahepatic portosystemic shunt in a cirrhotic patient. Intractable Rare Dis Res 2016;5(1):58-60

7 Laleman W, Simon-Talero M, Maleux G, et al. EASL-CLIF-Consortium. Embolization of large spontaneous portosystemic shunts for refractory hepatic encephalopathy: a multicenter survey on safety and efficacy. Hepatology 2013;57(6):2448-2457

8 Córdoba J, Mínguez B. Hepatic encephalopathy. Semin Liver Dis 2008;28(1):70-80

9 Shawcross DL, Olde Damink SW, Butterworth RF, Jalan R. Ammonia and hepatic encephalopathy: the more things change, the more they remain the same. Metab Brain Dis 2005;20(3):169-179
10 Córdoba J. New assessment of hepatic encephalopathy. J Hepatol 2011;54(5):1030-1040

11 Thornton, K. Evaluation and Prognosis of Patients with Cirrhosis. [Online Article] 2018 09/17/2019; 24].

12 Riggio O, Ridola L, Pasquale C, et al. A simplified psychometric evaluation for the diagnosis of minimal hepatic encephalopathy. Clin Gastroenterol Hepatol 2011;9(7):613-6.e1

13 Goldbecker A, Weissenborn K, Hamidi Shahrezaei G, et al. Comparison of the most favoured methods for the diagnosis of hepatic encephalopathy in liver transplantation candidates. Gut 2013;62(10):1497-1504

14 Ong JP, Aggarwal A, Krieger D, et al. Correlation between ammonia levels and the severity of hepatic encephalopathy. Am J Med 2003;114(3):188-193

15 D'Amico G, Garcia-Tsao G, Pagliaro L. Natural history and prognostic indicators of survival in cirrhosis: a systematic review of 118 studies. J Hepatol 2006;44(1):217-231

16 Saad WE. Portosystemic shunt syndrome and endovascular management of hepatic encephalopathy. Semin Intervent Radiol 2014;31(3):262-265

17 Guillaume M, Bureau C. Should the presence of spontaneous portosystemic shunts be implemented to the model for end-stage liver disease score for a better prediction of outcome. ? Gastroenterology 2018;154(6):1569-1571

18 Philips CA, Kumar L, Augustine P. Shunt occlusion for portosystemic shunt syndrome related refractory hepatic encephalopathy-a single-center experience in 21 patients from Kerala. Indian J Gastroenterol 2017;36(5):411-419

19 Nguyen DL, Morgan T. Protein restriction in hepatic encephalopathy is appropriate for selected patients: a point of view. Hepatol Int 2014;8(2, S2) :447-451

20 Iris W. Liou, H.N.K. Diagnosis and Management of Hepatic Encephalopathy. [Electronic ] 2018 04/12/18 [cited 2019 09/17/2019]; Section 3, Topic 4:[

21 Khungar V, Poordad F. Hepatic encephalopathy. Clin Liver Dis 2012;16(2):301-320

22 Pereira K, Carrion AF, Salsamendi J, Doshi M, Baker R, Kably I. Endovascular management of refractory hepatic encephalopathy complication of transjugular intrahepatic portosystemic shunt (tips): comprehensive review and clinical practice algorithm. Cardiovasc Intervent Radiol 2016;39(2):170-182

23 Sanyal A, Younossi ZM, Bass NM, et al. Randomised clinical trial: rifaximin improves health-related quality of life in cirrhotic patients with hepatic encephalopathy - a double-blind placebo-controlled study. Aliment Pharmacol Ther 2011;34(8):853-861

24 Yin X, Zhang F, Guo H, et al. A nomogram to predict the risk of hepatic encephalopathy after transjugular intrahepatic portosystemic shunt in cirrhotic patients. Sci Rep 2020;10(1):9381

25 Bai M, Qi X, Yang Z, et al. Predictors of hepatic encephalopathy after transjugular intrahepatic portosystemic shunt in cirrhotic patients: a systematic review. J Gastroenterol Hepatol 2011;26(6):943-951 
26 Casadaban LC, Parvinian A, Minocha J, et al. Clearing the confusion over hepatic encephalopathy after TIPS creation: incidence, prognostic factors, and clinical outcomes. Dig Dis Sci 2015;60(4):1059-1066

27 Chung H-H, Razavi MK, Sze DY, et al. Portosystemic pressure gradient during transjugular intrahepatic portosystemic shunt with Viatorr stent graft: what is the critical low threshold to avoid medically uncontrolled low pressure gradient related complications? J Gastroenterol Hepatol 2008;23(1):95-101

28 Patil R, Rassameehiran S, Patel R, Balakrishnan M, Sood GK. Embolization for closure of spontaneous porto-systemic shunts in patient with cirrhosis and refractory hepatic encephalopathy: a systematic review and meta-analysis. Gastroenterology 2017;152(5):S1140

29 Pattynama PM, Wils A, van der Linden E, van Dijk LC. Embolization with the Amplatzer vascular plug in TIPS patients. Cardiovasc Intervent Radiol 2007;30(6):1218-1221

30 Basseri S, Lightfoot CB. Balloon-occluded retrograde transvenous obliteration for treatment of bleeding gastric varices: case report and review of literature. Radiol Case Rep 2016;11(4):365-369

31 Madoff DC, Wallace MJ. Reduced stents and stent-grafts for the management of hepatic encephalopathy after transjugular intrahepatic portosystemic shunt creation. Semin Intervent Radiol 2005;22(4):316-328

32 Riggio O, Nardelli S, Moscucci F, Pasquale C, Ridola L, Merli M. Hepatic encephalopathy after transjugular intrahepatic portosystemic shunt. Clin Liver Dis 2012;16(1):133-146

33 Cookson DT, Zaman Z, Gordon-Smith J, Ireland HM, Hayes PC. Management of transjugular intrahepatic portosystemic shunt (TIPS)-associated refractory hepatic encephalopathy by shunt reduction using the parallel technique: outcomes of a retrospective case series. Cardiovasc Intervent Radiol 2011;34(1):92-99

34 Sze DY, Hwang GL, Kao JS, et al. Bidirectionally adjustable TIPS reduction by parallel stent and stent-graft deployment. J Vasc Interv Radiol 2008;19(11):1653-1658

35 Hauenstein KH, Haag K, Ochs A, Langer M, Rössle M. The reducing stent: treatment for transjugular intrahepatic portosystemic shunt-induced refractory hepatic encephalopathy and liver failure. Radiology 1995;194(1):175-179

36 Schultheiss M, Bettinger D, Boettler T, Thimme R, Rössle M. Severe hepatic encephalopathy after transjugular intrahepatic portosystemic shunt (TIPS): value of shunt reduction and occlusion. JSM Hepat 2017;2(1):1009

37 Pieper CC, Sprinkart AM, Nadal J, et al. Postinterventional passive expansion of partially dilated transjugular intrahepatic portosystemic shunt stents. J Vasc Interv Radiol 2015;26(3):388-394

38 Miraglia R, Maruzzelli L, Di Piazza A, et al. Transjugular intrahepatic portosystemic shunt using the new Gore Viatorr controlled expansion endoprosthesis: prospective, single-center, preliminary experience. Cardiovasc Intervent Radiol 2019;42(1):78-86

39 Blue RC, Lo GC, Kim E, et al. Transjugular intrahepatic portosystemic shunt flow reduction with adjustable polytetrafluoroethylene-covered balloon-expandable stents using the "sheath control" technique. Cardiovasc Intervent Radiol 2016;39(6):935-939

40 Jacquier A, Vidal V, Monnet O, et al. A modified procedure for transjugular intrahepatic portosystemic shunt flow reduction. J Vasc Interv Radiol 2006;17(8):1359-1363

41 Kroma G, Lopera J, Cura M, Suri R, El-Merhi F, Reading J. Transjugular intrahepatic portosystemic shunt flow reduction with adjustable polytetrafluoroethylene-covered balloonexpandable stents. J Vasc Interv Radiol 2009;20(7):981-986

42 Fanelli F, Salvatori FM, Rabuffi P, et al. Management of refractory hepatic encephalopathy after insertion of TIPS: long-term results of shunt reduction with hourglass-shaped balloon-expandable stent-graft. AJR Am J Roentgenol 2009;193(6):1696-1702

43 Angeloni S, Merli M, Salvatori FM, et al. Polytetrafluoroethylene-covered stent grafts for TIPS procedure: 1-year patency and clinical results. Am J Gastroenterol 2004;99(2):280-285

44 Haskal ZJ, Middlebrook MR. Creation of a stenotic stent to reduce flow through a transjugular intrahepatic portosystemic shunt. J Vasc Interv Radiol 1994;5(6):827-829

45 Madoff DC, Perez-Young IV, Wallace MJ, Skolkin MD, Toombs BD. Management of TIPS-related refractory hepatic encephalopathy with reduced Wallgraft endoprostheses. J Vasc Interv Radiol 2003;14(3):369-374

46 An J, Kim KW, Han S, Lee J, Lim YS. Improvement in survival associated with embolisation of spontaneous portosystemic shunt in patients with recurrent hepatic encephalopathy. Aliment Pharmacol Ther 2014;39(12):1418-1426

47 Ibukuro K, Sugihara T, Tanaka R, et al. Balloon-occluded retrograde transvenous obliteration (BRTO) for a direct shunt between the inferior mesenteric vein and the inferior vena cava in a patient with hepatic encephalopathy. J Vasc Interv Radiol 2007;18(1 Pt 1) :121-125

48 Koito K, Namieno T, Nagakawa T, Morita K. Balloon-occluded retrograde transvenous obliteration for gastric varices with gastrorenal or gastrocaval collaterals. Am J Roentgenol 1996;167(5):1317-1320

49 Chang M-Y, Kim MD, Kim T, et al. Plug-assisted retrograde transvenous obliteration for the treatment of gastric variceal hemorrhage. Korean J Radiol 2016;17(2):230-238

50 Kim T, Yang H, Lee CK, Kim GB. Vascular plug assisted retrograde transvenous obliteration (PARTO) for gastric varix bleeding patients in the emergent clinical setting. Yonsei Med J 2016;57(4):973-979

51 Kim DJ, Darcy MD, Mani NB, et al. Modified balloon-occluded retrograde transvenous obliteration (BRTO) techniques for the treatment of gastric varices: vascular plug-assisted retrograde transvenous obliteration (PARTO)/coil-assisted retrograde transvenous obliteration (CARTO)/balloon-occluded antegrade transvenous obliteration (BATO) Cardiovasc Intervent Radiol 2018;41(6):835-847

52 Lee EW, Saab S, Gomes AS, et al. Coil-assisted retrograde transvenous obliteration (CARTO) for the treatment of portal hypertensive variceal bleeding: preliminary results. Clin Transl Gastroenterol 2014;5(10):e61-e61

53 Marsala A, Lee E. Coil-assisted retrograde transvenous obliteration: a valid treatment for gastric variceal hemorrhage and hepatic encephalopathy. Digestive Disease Interventions 2018;01(4):302-305

54 Philips CA, Rajesh S, Augustine P, Padsalgi G, Ahamed R. Portosystemic shunts and refractory hepatic encephalopathy: patient selection and current options. Hepat Med 2019;11:23-34

55 Lynn AM, Singh S, Congly SE, et al. Embolization of portosystemic shunts for treatment of medically refractory hepatic encephalopathy. Liver Transpl 2016;22(6):723-731

56 Gaba RC. Retrograde-antegrade accelerated trap obliteration: a modified approach to transvenous eradication of gastric varices. J Vasc Interv Radiol 2017;28(2):291-294

57 Naeshiro N, Kakizawa H, Aikata H, et al. Percutaneous transvenous embolization for portosystemic shunts associated with encephalopathy: long-term outcomes in 14 patients. Hepatol Res 2014;44(7):740-749

58 Lipnik AJ, Pandhi MB, Khabbaz RC, Gaba RC. Endovascular treatment for variceal hemorrhage: TIPS, BRTO, and combined approaches. Semin Intervent Radiol 2018;35(3):169-184 